\title{
Potential Application of Bacillus sp. SDNS Gold Nanoparticles
}

\author{
Samia Saad Abouelkheir*, Nermeen Ahmed El-Sersy, and Soraya Abdel-Fatah Sabry \\ National Institute of Oceanography and Fisheries (NIOF), Marine Microbiology Lab., \\ Kayet Bay, El-Anfushy, Alexandria, Egypt
}

*Corresponding author

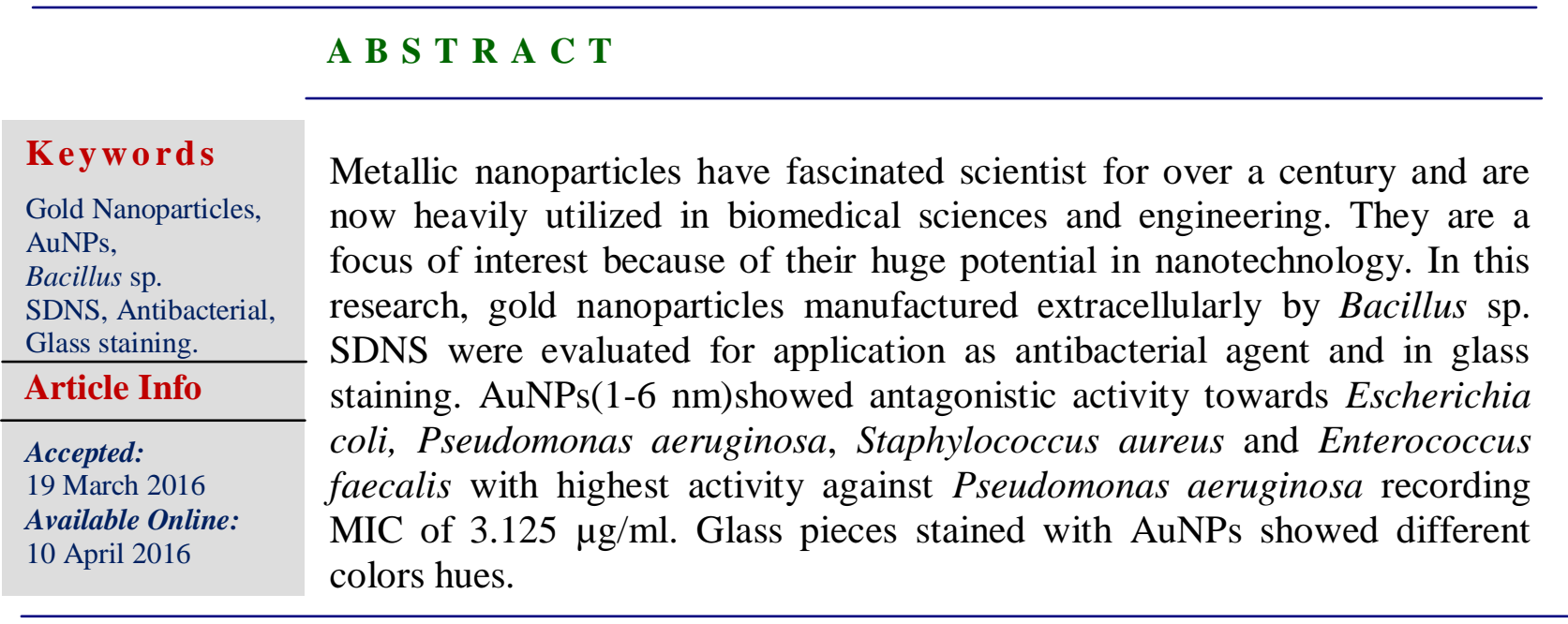

\section{Introduction}

Gold nanoparticles (AuNPs) gained attention due to their application in different fields of science (Ngo, et al., 2012). The featured optical property of AuNPs makes them totally helpful in the biomedicine. The usage of metallic nanoparticles is a promised approach to disband the dilemma of antibiotic resistance (Hema et al., 2012). Owing to their tiny size and high surface-tovolume ratio $(\mathrm{S} / \mathrm{V})$, nanoparticles have a large contact area with microorganisms and thus promote its antimicrobial efficiency. Metallic nanoparticles are also masterful in targeting various bacterial structures (Priyadarshini et al., 2014).
AuNPs have been reported as non-toxic parallel to other metallic nanoparticles such as silver and platinum nanoparticles (Lee et al., 2010; Asharani et al., 2011).

Thirumurugan et al. (2012) produced AuNPs from Bacillus subtilis and were estimated for their antifungal and antibacterial efficacy. The potential activity of gold nanoparticles versus microbial pathogens depends fundamentally on the shape and size of the particles (Kagithoju et al., 2012). It neatly connects to surface of the microorganisms causing apparent deterioration to the cells (Grace and Pandian, 2007). 
AuNPs create holes in the cell wall, resulting in the seepage of cell contents leading to death, in another route it can bind to the bacterial DNA and inhibits its transcription (Rai et al., 2010). Millenbaugh et al., (2015) utilized gold nanospheres in targeting and killing of Staphylococcus aureus. Lima et al., (2013) declared that AuNPs eliminate $90-95 \%$ of Escherichia coli and Salmonella typhi colonies. Prema and Thangapandiyan, (2013) stated that AuNPs could act as an efficient antibacterial agent and established as a substitution for the growth of novel antibacterial drugs to conflict resistance problem. The antibacterial activities of drugs-capped AuNPs against strains of Gram-negative and Gram-positive microorganisms were investigated (Sadowski and Maliszewska, 2011).

A well-known application of early nanotechnology is the ruby red color that was utilized for stained glass windows during the middle Ages (Horikoshi and Serpone, 2013). Au nanoparticles were successfully deposited on silica spheres by the electroless metal plating technique (Kobayashi et al., 2005).Immobilizing the nanoparticles on supports such as powders and plates is a candidate to prevent the aggregation. An electroless metal plating technique can make metallic films plated on insulating support materials such as glass plates (Kobayashi and Ishii, 2013a,b).

It was aimed in this work to evaluate the potentiality of gold nanoparticles manufactured by a marine bacterium as an antibacterial agent and also its possible use in glass staining.

\section{Materials and Methods}

\section{Gold Nanoparticles (AuNPs)}

The gold nanoparticles used in this study were biosynthesized extracellularly from the marine Bacillus sp. SDNS (Abouelkheir, 2015). Their size ranged between 1-6 nm.

\section{Bacterial Indicator Strains}

The antibacterial activity of fabricated gold nanoparticles was examined against four indicator strains; the Gram negative Pseudomonas aeruginosa; ATCC @: 15442, and Escherichia coli; 8739 and the Gram positive Staphylococcus aureus; 25923, and Enterococcus faecalis; 29212 obtained from the Public Health England (PHE) Culture Collections, Selectrol.

\section{Preparation of AuNPs}

Bacillus sp. SDNS was cultured in nutrient broth in shaker incubator at $\mathrm{pH} 7$ and $30{ }^{\circ} \mathrm{C}$ for $24-48 \mathrm{~h}$ and cells were separated by centrifugation at $5000 \mathrm{rpm}$ for $20 \mathrm{~min}$. Ten $\mathrm{ml}$ of bacterial supernatant were added to 20 $\mathrm{mL}$ of $1 \times 10^{-3} \mathrm{M}$ aqueous $\mathrm{HAuCl}_{4}$ solution in a $250 \mathrm{ml}$ Erlenmeyer flask. The mixture was left in a shaker incubator at $30^{\circ} \mathrm{C}$ for a further 24-72 h. The formed AuNPs were obtained by centrifugation, washed and suspended in distilled water. The gold nanoparticles were characterized and size was determined using FTIR, XRD, TEM and EDX (Abouelkheir, 2015).

\section{Antibacterial Activity of Gold Nanoparticles (AuNPs)}

\section{Agar Diffusion Well-Method}

Bacterial indicator strains were cultured in nutrient broth till mid exponential phase. Inocula were uniformly spread on nutrient agar plates and wells $(1 \mathrm{~cm}$ diameter) were cut in the agar and filled with different concentrations $(50,100,200 \mu \mathrm{L})$ of previously prepared AuNPs. Plates were incubated for $24 \mathrm{~h}$ at $37^{\circ} \mathrm{C}$ under aerobic conditions. Zone of inhibition was measured 
in $\mathrm{mm}$. Tests were performed in triplicate (Valgas et al., 2007).

\section{Minimum Inhibitory Concentration (MIC) Determination}

The microdilution method (Valgas et al., 2007) was utilized. In each well, $990 \mu 1$ of nutrient broth were inoculated with $10 \mu \mathrm{l}$ of exponentially growing cells. From a stock solution $(0.4 \mathrm{mg} / \mathrm{ml})$, AuNPs were added to reach concentrations ranging from 0.2 to $0.3910^{-3} \mathrm{mg} / \mathrm{ml}$, one well without inoculation was kept as control. Incubation was done for $24 \mathrm{~h}$ at $37^{\circ} \mathrm{C}$. MIC $(\mu \mathrm{g} / \mathrm{ml})$ was defined as the lowest concentration of AuNPs, which completely inhibited bacterial growth. All experiments were accomplished in triplicate.

\section{Glass Staining with Gold Nanoparticles (AuNPs)}

\section{Synthesis of Gold Nanoparticle/ polyvinyl Alcohol (PVA) Solution}

PVA solid was slowly added to the warm gold nanoparticles solutions to make $4.5 \%$ (w/v) solution. The solutions were heated gently to dissolve the PVA and decanted into silicone bake molds (Duncan et al., 2010).

\section{Preparation of the Nanostained Glass Pieces}

About $5 \mathrm{~mL}$ of AuNPs/PVA were poured into silicone bake molds, enough to cover the bottom of the mold.

Water was then evaporated by leaving to dry overnight or the solutions were heated in an oven at $200^{\circ} \mathrm{C}$. Nanostained "glass" disks with different color hues (red to purple) were then removed from molds (Duncan et al., 2010).

\section{Results and Discussion}

Nanoparticles of gold and silver display a special optical feature as surface plasmon resonance (SPR) absorption, which mainly depends on particle shape, size and surface condition. Therefore, to take whole advantage of surface, a decrease in their particle size is important because total surface area of metal increases with the decrease in size (Kobayashi \& Ishii, 2013a).

\section{Antibacterial Activity}

The nanoscale allows the materials with the ability to permeate into different biological membranes, such as bacterial cell walls, elevating bactericidal effects (Nuñez-Anita et al., 2014). Antimicrobials comprise not just antibiotics, but synthetically formed compounds (Patel et al., 2012; Dixit et al., 2015). AuNPs synthesized from Bacillus sp. SDNS exhibited antagonistic effect against all indicator strains tested with variable degrees depending on the bacterial species (Figs.1, 2). MICs of 3.125 and 6.25 were recorded for Pseudomonas aeruginosa, and Escherichia coli, respectively, whereas $50 \mu \mathrm{g} / \mathrm{ml}$ was recorded for Enterococcus faecalis and Staphylococcus aureus (Fig.1). Grace \& Pandian (2007) investigated the antibacterial efficiency of antibiotics-coated gold nanoparticles against diverse strains of Gram-positive and Gram-negative bacteria like Staphylococcus aureus, Micrococcus luteus, Pseudomonas aeruginosa, and Escherichia coli. However, in the present case the reason beyond the selective antibacterial activity might be imputed to the differences in the cell wall structure between gram positive and negative bacteria. Since Gram negative bacteria are less susceptible to antibiotics, it is thus possible that the gold nanoparticles synthesized by the marine bacteria may provide an effective means towards inhibiting the disease caused by the gram negative bacterial strains. 
Fig.1 Zone of Inhibition (mm) Produced by AuNPs Tested against Indicator Strains after $24 \mathrm{~h}$ Incubation at $37^{\circ} \mathrm{C}$

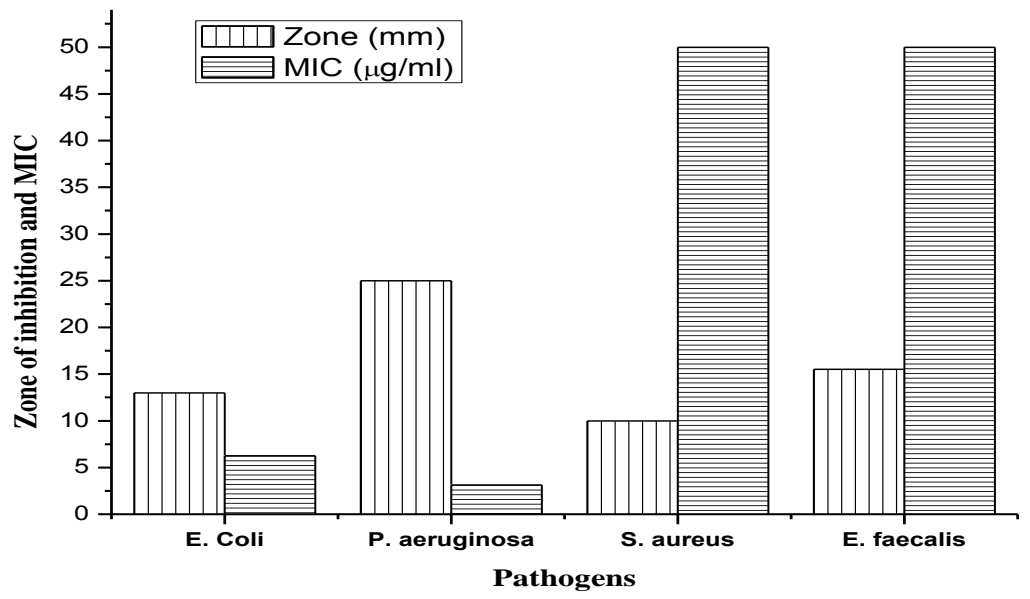

Fig.2 Effect of Bacillus sp. SDNS AuNPs on Bacterial Indicator Strains
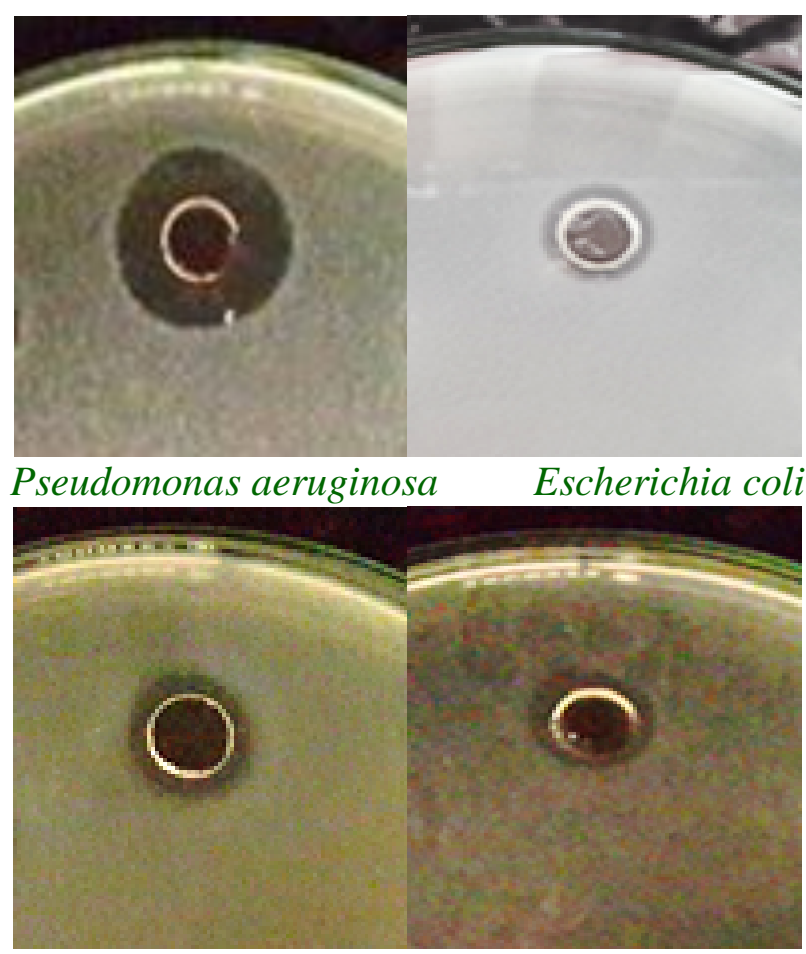

Staphylococcus aureus Enterococcus faecalis 
Fig.3 Au-glass Crystals, AuNPs were Deposited as Plastic Disks using Air (a),Au-glass Crystals using Oven-drying Process at $200^{\circ} \mathrm{C}$ for $2 \mathrm{~h}$ (b)

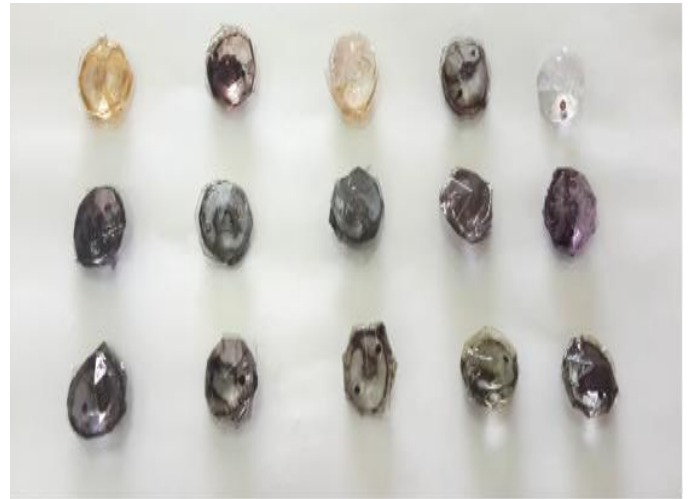

A

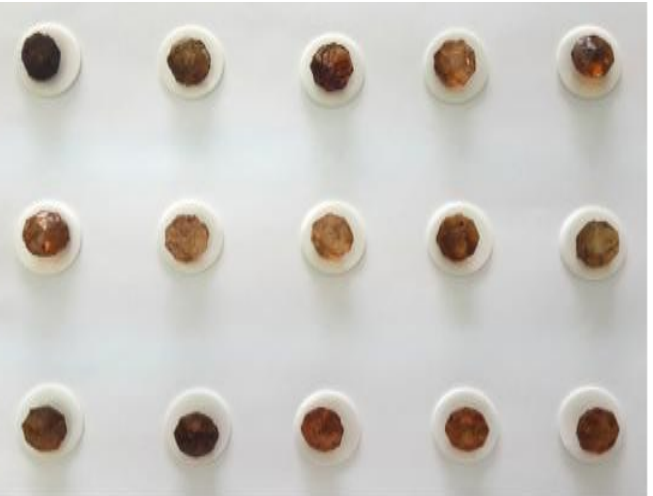

B

\section{Glass Staining}

Glass is made from melted sand $\left(\mathrm{SiO}_{2}\right)$ and need a high temperature, about $1371.1^{\circ} \mathrm{C}$ to melt so, artisans adding additional ingredients to help sand to melt at a much lower temperature. A mixture of sand, potash, soda ash, lime and lead oxide melt the sand to temperatures around $815.6{ }^{\circ} \mathrm{C}$. Once this mixture molten, coloring agents, or colorants, are added. Artisans observed that different compounds gave rise to different colors. For example, ruby glass was created by adding gold chloride, while green or brown glass was created by adding iron oxides (Zenner, 2008).

During the experimental work, a wide variation of colors was noticed for AuNPs colloidal solutions produced according to the different reaction conditions. Based on this observation different stained glass pieces were made using the colorant agent AuNPs. AuNPs/PVA metallic films plated on glass crystals were synthesized by air drying or heating in oven at about $200^{\circ} \mathrm{C}$ for 2 h (Fig.3). Similarly, Au nanoparticles were successfully deposited on silica spheres by the electroless metal plating technique (Kobayashi et al., 2005) and on glass plates (Au-glass) (Kobayashi and Ishii, 2013b).

\section{References}

Abouelkheir, S.S. 2015. Gold Nanoclusters from Bacillus sp. SDNS and Their Applications.PhD thesis, Faculty of Science, Alexandria University.

Asharani, P.V., Lianwu, Y., Gong, Z., Valiyaveettil, S. 2011. Comparison of the toxicity of silver, gold and platinum nanoparticles in developing zebra fish embryos. Nanotoxicol., 5(1): 43-54.

Dixit, R., Halve, A.K., Shinde, C.P., Soni, P.K. 2015. Synthetic and Antimicrobial Activity of 4 Thiazolidinones. Int. J. Curr. Pharma. Res., 7(3): 92-94.

Duncan, K.A., Johnson, C., McElhinny, K., Ng, S., Cadwell, K.D., Petersen, G.M.Z., Johnson, A., Horoszewski, D., Gentry, K., Lisensky, G., Crone, W.C. 2010. Art as an avenue to science literacy: Teaching nanotechnology through stained glass. J. Chem. Edu., 87(10): 10311038.

Grace, N.G., Pandian, K. 2007. Antibacterial efficacy of aminoglycosidic antibiotics protected gold nanoparticles - a brief study. Colloids and Surfaces A: 
Physicochem. Engi. Aspects, 297(1): 63-70.

Hema, T.A., Shiny, M., Parvathy, J. 2012. Antimicrobial activity of leaves of Azima tetracantha against clinical pathogens. Int. J. Pharm. Pharma. Sci., 4(4): 317-319.

Horikoshi, S., Serpone, N. 2013. Introduction to Nanoparticles in: Microwaves in Nanoparticle Synthesis, Fundamentals and Applications, Wiley-VCH Verlag, Weinheim.

Kagithoju, S., Godishala, V., Pabba, S.K., Kurra, H.B., Rama, S.N. 2012. Antibacterial activity of flower extract of Pongamia pinnata Linn An elite medicinal plant. Int. $J$. Pharm. Pharma. Sci., 4(3): 130-132.

Kobayashi, Y., Ishii, Y. 2013b. Electroless deposited gold nanoparticles on glass plates as sensors for measuring the dielectric constant of solutions. $J$. Nanoparticles, Volume 2013, Article ID 841582, 5 pages.

Kobayashi, Y., Ishii, Y. 2013a. Fabrication of Gold Nanoparticles-Deposited Glass Plate by Electroless Metal Plating Technique and Immobilization of Proteins on It. Int. Conference on Innovations in Engi. Technol., (ICIET), 25(26): 233-236.

Kobayashi, Y., Tadaki, Y., Nagao, D., Konno, M. 2005. Deposition of gold nanoparticles on silica spheres by electroless metal plating technique. J. Colloid and Interface Sci., 283(2): 601-604.

Lee, S.M., Song, K.C., Lee, B.S. 2010. Antibacterial activity of silver nanoparticles prepared by a chemical reduction method. Korean J. Chem. Engi., 27: 688-692.

Lima, E., Guerra, R., Lara, V., Guzmán, A. 2013. Gold nanoparticles as efficient antimicrobial agents for Escherichia coli and Salmonella typhi. Chem. Central J., 7(11): 1-7.

Millenbaugh, N.J., Baskin, J.B., DeSilva, M.N., Elliott, W.R., Glickman, R.D. 2015. Photothermal killing of Staphylococcus aureus using antibody-targeted gold nanoparticles. Int. J. Nanomed., 10: 1953-1960.

Ngo, Y.H., Li, D., Simon, G.P., Garnier, G. 2012. Gold nanoparticle-paper as a three-dimensional surface enhanced raman scattering substrate. Langmuir, 28(23): 8782-8790.

Nuñez-Anita, R.E., Acosta-Torres, L.S., Vilar-Pineda, J., Martínez-Espinosa, J.C., Fuente-Hernández, J.D., Castaño, V.M. 2014. Toxicology of antimicrobial nanoparticles for prosthetic devices. Int. J. Nanomed., 9: 3999-4006.

Patel, D.S., Patel, B.K., Patel, H.B. 2012. Biological screening of Antimicrobial Agents. Lambert Academic Publishing. 1-68.

Prema, P., Thangapandiyan, S. 2013. Invitro Antibacterial Activity of Gold Nanoparticles Capped withPolysaccharide Stabilizing Agents. Int. J. Pharm. Pharma. Sci., 5(1): 310-314.

Priyadarshini, E., Pradhan, N., Sukla, L.B., Panda, P.K. 2014. Controlled Synthesis of Gold Nanoparticles Using Aspergillusterreus IF0 and Its Antibacterial Potential against Gram Negative Pathogenic Bacteria. $J$. Nanotechnol., 1-9.

Rai, A., Prabhune, A., Perry, C.C. 2010. Antibiotic mediated synthesis of gold nanoparticles with potent antimicrobial activity and their application in antimicrobial coatings. J. Materials Chem., 20(32): 67896798.

Sadowski, Z., Maliszewska, I.H. 2011. Applications of Gold Nanoparticles: 
Current Trends and Future Prospects

In: Metal Nanoparticles in Microbiology. Rai, M., \& Duran, N. (eds.), 1st edn, Springer, Berlin Heidelberg.225-248.

Thirumurugan, A., Ramachandran, S., Tomy, N.A., Jiflin, G.J., \& Rajagomathi, G. (2012).Biological synthesis of gold nanoparticles by Bacillus subtilis and evaluation of increased antimicrobial activity against clinical isolates. Korean $J$. Chem. Engi., 29(12): 1-5.

Valgas, C., Souza, S.M.D., Smania, E.F.A., Jr, A.S. 2007. Screening methods to determine antibacterial activity of natural products. Brazilian $J$. Microbiol., 38(2): 369-380.

Zenner, G.M. 2008. Nanoparticle stained glass. University of WisconsinMaterials Research Science and Engineering Center.1-28.

\section{How to cite this article:}

Samia Saad Abouelkheir, Nermeen Ahmed El-Sersy, and Soraya Abdel-Fatah Sabry. 2016. Potential Application of Bacillus sp. SDNS Gold Nanoparticles. Int.J.Curr.Microbiol. App.Sci.5(4): 546-552. doi: http://dx.doi.org/10.20546/ijcmas.2016.504.062 